present. There are no characteristic auscultatory signs. The $\mathrm{X}$-ray picture shows a dilated pulmonary artery in contradistinction to the concavity of the Fallot. Right axis is present in the electrocardiogram.

\section{Pulmonary Stenosis}

Pulmonary stenosis may be either valvular or infundibular, and the greater number of cases are complicated by septal defects, and form part of the tetralogy of Fallot. There are however a relatively few cases which arise either as a foetal endocarditis, or as a developmental abnormality. The forgmen ovale is usually open. The striking physical sign is a loud, rasping, systolic murmur

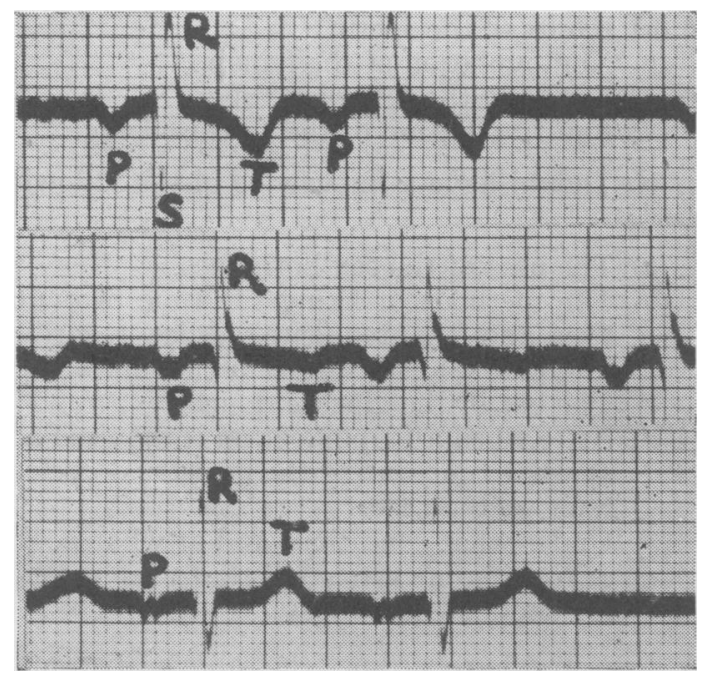

Dextrocardia. Inversion of $\mathrm{P}$ and $\mathrm{T}$ waves in leads $\mathrm{I}$ and 2.

in the second left space with corresponding systolic thrill. The bruit is conducted towards the left clavicle. The $\mathrm{X}$-ray picture shows dilatation of the pulmonary artery or conus, and the electrocardiogram a right axis. Cyanosis is absent or late in appearance, and rarely reaches a high degree.

\section{Tricuspid Atresia}

This lesion may be a cause of very severe cyanosis. There are usually no murmurs, and the $\mathrm{X}$-ray picture shows a small pulmonary artery and right ventricle. It has the distinction of being the only congenital cyanotic lesion with a left axis in the electrocardiogram.

\section{STERILITY IN PRACTICE}

\section{An Editorial Commentary}

The advent of clinics and specialisation has $\underset{\vec{*}}{\vec{A}}$ done much to rob the general practitioner of his $\stackrel{5}{\rightarrow}$ interest in this most fascinating of subjects. It? is suggested that he should still occupy an important $\frac{\bar{F}}{\bar{C}}$ position in the team necessary for the proper $\frac{\vec{\Phi}}{\vec{\sigma}}$ investigation and treatment of infertility. There $\triangle$ is none better fitted than himself for tackling $\%$ a condition in which the knowledge of the home $\vec{O}$ life and of the habits of the couple concerned, and frequently those of the previous generation, are of $\vec{\omega}$ paramount importance in the disentanglement of $\stackrel{\sigma}{\circ}$ the many and varied causes of the infertile marriage. $\stackrel{0}{7}$ $\mathrm{He}$ is all the more necessary since many women 3 . still feel that there is some sort of stigma attached ${ }_{-}^{N}$ to this state of barrenness. This stigma may in i part be associated with the teachings of the Biblece "God has taken away my reproach," cried Rachel after pregnancy had succeeded her infertility. $\omega$ The modern Rachel prefers to approach the friendly 9 atmosphere of the family physician rather than $\overrightarrow{0}$ that of the somewhat austere surroundings of $a_{\mathbb{D}}$ clinic.

However, those associated with a sterility $\frac{\mathbb{}}{3}$ clinic cannot fail but to notice that many prac titioners are still confused regarding their methof of approach to the subject. ... How often has the patient merely been told to "Take a good holiday ... or has been handed some form of glandular tablet without any previous examination or investigation? Much worse still, she may have been subjected to curettage and treatment in the absence of any proper tests regarding her husband's potency. $\mathbb{\perp}$ This latter procedure should be condemned as a grave professional misdemeanour.

This short article will endeavour to help the practitioner as to how far he should go with his own investigations before calling in other help. The scope of these few words will not allow of $\frac{3}{3}$ more than a few pointers for the doctor and of a few "Do's and Don'ts": Discussion of the multi- 3 . tudinous fertility factors and their respective treatments would call for many hundreds of pages. The result of condensation may lay the author 0 open to the criticism of dogmatism, to which this is his only defence. That the matter under? discussion is an important one and that it has been rendered even more important owing to the $N$ ravages of war is something about which we shall N all agree. In America, for example, it is stated $N$ that there are about five million infertile marriages ${ }_{\sigma}^{\omega}$ (Popenhoe, I943). Other statisticians claim that sterile unions form as many as 15 per cent of the $\stackrel{0}{=}$ total marriages. Other experts such as Titus and Hamblen (I935) state that from 25 to 50 per cent 
of sterile marriages are rendered fruitful after proper investigation, diagnosis and treatment. Take these two sets of statements into consideration and it will be realised that there is a vast field for the sterility expert and one in which he may achieve much success given care and knowledge.

Before turning to the practical points of the subject it is proposed to make a few generalities.

The sterile marriage and not the sterile individual is the problem which confronts you.

The male partner of the marriage is responsible for at least 40 per cent. of childlessness. Michelson (I943) places this as high as 65 per cent.

Failure to reproduce may be due to the culmutative effects of many minor sterility factors, which taken singly, would not prove to be sufficient to lower the reproductive capacity of the partner. Therefore, examine your patients most thoroughly from the medical point of view.

"A marriage should not be considered to be sterile until at least three years have passed." This statement appears to be made in nearly every article on the subject and the author of this note begs to differ from it most emphatically. Regular sex life with normal potent partners should always produce offspring. within a few months: failure to achieve this result calls for a careful investigation in order that valuable time may be saved. In considering this statement, with which some may disagree, recall that in the human being, fertile copulation is dependent on ovulation, whereas in certain animals such as the rabbit, ovulation is dependant on copulation (the rabbit ovulating some nine and a half hours after intercourse) (Marshall, I925). Remember that ignorance of the time of conception is a common cause of sterility-ovulation, like time, waits for no man! Couples with erroneous beliefs regarding the fertile period, may from over-zealousness in attempting to time ovulation accurately, indulge in intercourse at the wrong times of the menstrual cycle. In this manner a marriage may be rendered barren.

Turning to the biological angle for a moment, note that the most fertile marriages usually result from the union of opposites. Weininger once made the statement that "There are no men, there are no Women, but only sexual majorities." By way of explanation consider the mannish types of women genius in the past: George Sands, Catherine the Great, Rosa Bonheur, etc., "They shave as well as shine" was the comment of H. L. Mencken. Therefore, when examining either partner note the secondary sex characteristics, the fat distribution, the hair distribution and form an opinion as to whether the partner in question is an "Opposite" or whether he or she approximates towards the neutral line, and is lacking in fecundity.
"The degree of success in the understanding and in the treatment of sterility is proportional to the outlay of attention to the plurality of the factors which may be involved" Pomerenke (r945). General attention to health must accompany all specific treatment directed towards any faults in the generative tract.

We must now turn to the practical angle as to what a general practitioner may reasonably be expected to do when faced with a childless couple.

I. A careful history must be entered on a case sheet from the interrogation of both partners of the marriage.

2. A thorough and complete medical overhaul must be made of both husband and wife.

3. He should give a careful consideration into the causes of sterility and it is suggested he make them under the following headings:

(a) Faults of the sperm.

(b) Non-ovulation of the female.

(c) Faults in the fallopian tubes.

(d) Faulty nidation of the fertilised egg.

4. He should have a knowledge of the following factors:

(a) The uses of the sex hormones.

(b) The methods of fixing the time of ovula $\frac{}{3}$ tion and the requisite advice regarding $\mathbb{D}$ intercourse resulting from this knowledge

(c) The use of the glucose douche.

(d) As to when a Salpingogram is required anc at what time during the menstrual cycle to refer such a case.

(e) Under what conditions and at what period during the menstrual cycle to refer a case for endometrial biopsy.

A few words regarding the above five main headings may help to clarify these requisites.

\section{The History}

A full and accurate history must be taken from both partners. This must contain essentially all the details regarding the duration and history of the present marriage. The sexual history regarding the frequency of intercourse, the use of contraceptives, etc., must be noted.

Sexual habits such as masturbation and whether or no orgasm occurs are points of importance.

The degree of prolificacy of near relatives on $N$ both sides of the family is information of value.

The pre-marital sex life, illnesses of childhood and $\mathbb{N}$ of adolescence with special reference to a history of $\mathrm{N}$ venereal disease, mumps, chronic infections, traumata to genitalia, etc., must be analysed.

The reproductive history of the female should $\frac{\mathbb{D}}{\varnothing}$ contain full details of the menstruation, of past $\stackrel{\mathscr{c}}{+}$ 
miscarriages, of evidence of ovulation (Mittelschmerz, spotting, increased discharge, etc.).

A full inquiry into the general habits with especial reference to overwork, alcohol, tobacco, drugs and douches should be registered. The taking of a proper history is a laborious business, but much assistance may be obtained by the use of a case history sheet as used at most of the clinics dealing with this condition.

\section{The General Examination}

A very thorough medical overhaul is absolutely necessary. Certain pathological tests may be found to be required, the commoner being the examination of the blood, the basal metabolic rate and the Wasserman reaction. Glandular dystrophia must be especially looked for. Also remember that many marriages are infertile because nature is safeguarding the life and safety of the female partner by rendering her sterile. The female partner may not be fit for childbearing and this general overhaul may disclose conditions which will oblige the physician to ban further attempts at conception.

\section{Local Examination}

(a) Male.-Examine the testicles. Are they soft and flabby from degenerative processes or are they indurated from chronic fibrosis? They should be of good size and have an elastic feel.

Are there any nodules in the vas? These may best be felt in the scrotal area and if found to be present are a sure sign of obstruction. Note whether there is a herniotomy scar which may be related to a damaged vas.

The prostate and vesicles should be examined per rectum for abnormality.

(b) Female.-A routine gynaecological examination should be made so that conditions under the following main headings may be excluded.

(a) Infections of the genital tract.

(b) Malpositions of the uterus or of the adnexa.

(c) Structural abnormalities.

(d) Inflammatory disease of the pelvic organs.

\section{Considerations of the main Causes of Infertility}

(a) The Sperm.-Examine a fresh masturbation specimen collected in a glass container (not a condom). A drop on a slide will tell you whether there is a high degree of motility. From 65 to
90 per cent of the sperms should be motile whether the sperm population is normal or abnormal (Hotchkiss I938 and W. W. Williams, I937).

$A$ Sperm Count is not a difficult procedure. Use a pipette as employed in the counting of white cells. Fill this to the mark and dilute with plain tap water. This will give a one in twenty dilution. The sperms may then be counted on a haemocytometer, taking the average of the number counted on about five large squares and multiplying this figure by five so as to obtain the number of millions per c.c. The numerical index may be taken as a fair guide to the fertility standard of the male under test. A count of seventy million should be sufficient to exclude the male partner, although a much higher count is desirable.

The recognition of pathological sperm populations requires experience and should not be attempted by the occasional worker.

Huhner's or Sims' post-coital test is a valuable and simple test for the practitioner to perform. The object of the test is to determine the degree of motility of the sperm when in contact with the secretions of the female genital tract. The examination is best carried out shortly after intercourse and preferably at the time of ovulation (see later). A vaginal speculum should be passed carefully and no lubricant should be employed. A drop of secretion should then be transferred fromb the cervical canal on to a glass slide. A wire loop is all that is required for this manouvreo When observing the presence of sperms and the degree of their motility look particularly at the periphery of the smear.

(b) Non-ovulation of the Female.-Does Mittelschmerz occur? Is there an increase of vaginal secretions, any spotting, breast tenderness or increase in nervous symptoms at or about fifteen days before the expected day of the next period?

Is an endometrial biopsy necessary in order to confirm the presence or absence of ovulation?

Remember that the non-ovulator frequently falls into a recognisable clinical type. She is frequently the masculine and less desirable woman with the male type of pelvis and other stigmata of her state.

(c) Faults of the Fallopian Tubes.-Tubal disease is a common cause of sterility and Irving (I936) places this as high as 20 per cent.

If in doubt the practitioner will arrange for a Salpingogram appreciating that this procedure has a high therapeutic as well as diagnostic value.

(d) Faulting Nidation of the Fertilised Egg. This is a subject in itself, and is only mentioned since under another heading we come to the suggestions for the use of sex hormones, which it is thought aid in the reinforcement of the nesting of the human egg. 


\section{Generalisations}

The use of the sex hormones have a very definite place in the treatment of those cases in which neither organic nor mechanical causes have been found. Ethisterone administered in $5 \mathrm{mgm}$. tablets one a day for the twelve days preceding a period will assist in the nidation of the fertilised egg. A considerable advance in this therapy has been suggested and practised by Christie Brown. $\mathrm{He}$ gives stilboestrol or better still dienoestrol (o.I mgm.) daily at the same time as the Ethisterone (corpus luteum). This at first sight appears to be unreasonable in as much as the tablets are reputed to be antagonistic. The practice is based on sound reasoning, however, and is highly successful. In an ovariectomised rat the uterus fails to grow when corpus luteum (Ethisterone) is administered. Add stilboestrol and growth takes place. This experimental work described in "Physiology of the Uterus" (Yeomans I944) forms the basis for Christie Brown's practice. Remember that thyroid given in small doses is frequently a valuable and useful stimulant to the complex workings of the ductless glands and that both the partners may benefit from this therapy.

The fixing of the time of ovulation may be easy or difficult. As mentioned previously, the average date is some fifteen days before the expected menstrual period. In some women the symptoms of Mittelschmerz, etc. make the diagnosis easy, in others none of the helpful symptoms are present. A daily rectal temperature may give the clue to this group. The drop in temperature preceding the luteal rise can be determined by an intelligent patient. The temperature must be taken accurately at the same time every day and the pre-luteal drop will be found fairly easily. It is at this time that ovulation occurs. That it is necessary to fix this time accurately is obvious since intercourse should then be confined to the day preceding and the day of ovulation. This point also arises if the procedure of artificial insemination is under consideration. Many interesting points centre around this subject of ovulation and in the opinion of many any intercourse between the time of ovulation and the subsequent period is bound to be sterile. In other words this is the "safe" period.

The use of the glucose douche is a very simple and sometimes highly useful and successful form of therapy. McLeod and Hotchkiss (I943) introduced this treatment finding that the motility of the sperm was enhanced when -it was placed in a balanced solution of glucose and saline. They published the case histories of twelve women with previous sterility of three years duration. These became pregnant after the use of this type of douche fluid. It is always worth trying and useful formula is as follows:

\begin{tabular}{llll} 
Glucose & $\ldots$ & $\ldots$ & $3 \mathrm{oz}$. \\
Sodium Chloride & $\ldots$ & I oz. \\
Calcium Chloride & $\ldots$ & gr. Io. \\
Pot. Chloride &.. & $\ldots$ & gr. Io. \\
Aq. ad & $\ldots$ & . & 8 oz. S. 3p oz. to \\
\multicolumn{4}{c}{} \\
To be used as & a vaginal douche.
\end{tabular}

Is. a Salpingogram necessary? I will repeat that the therapeutic effect of the investigation is a very definite entity. Never refer a case to the radio logist within a week of the period preceding of within ten days of the expected period if all risk $\frac{9 P}{8}$ embolism is to be avoided. Also make quite suce the patient is not pregnant. When referring the female for an endometrial biopsy a simple andp useful measure in order to make out whether shie ovulates or no, send her up two days before the expected menstrual period.

In conclusion the author of these few notes hopes that there may be therein found an occasional to for the practitioner, and that the reader may as a result take more interest in a subject which should not be wrested from his sphere, as is becoming the custom with so many subjects, such as rhe甲 matism, tuberculosis, venereal disease, etc., quote only a few. In fact, when one listenso to some zealots in the profession one is forced wonder what the true function of the gener practitioner should really be, unless to do the night work for the hyper-specialist.

Remember that there is a really great interest the long and difficult search into the many ang varied causes of sterility and that there is a ricio reward for successful treatment. "Give me chif dren or else I die" was the plaint of Rachel (Gene sis Xxix). Happily the modern Rachel is st with us and we should be glad to be able to help hes.

\section{Conclusions}

I. The general practitioner should play a muci. more important part in the diagnosis and treaffment of sterility cases.

2. In all cases of infertility he should institute proper investigations at a much earlier date tha is found to be the usual case.

3. He should arrange and perform the routinge tests before seeking specialist aid for the more complicated of his cases.

4. Certain routine tests are suggested and sond practical points are discussed.

\section{REFERENCES}

I. HAMBLEN, E. C., Facts for Childless Couples. (C. C. Thomas, Springfield, I942). I936). 
3. MACLEOD, J., and HOTCH KISS, R.S., Am. J. Obst. \& Gynae, 46, 424, I943.

5. POMMERENKE, W. T., West. J. Surg. Obst. \& Gynae, 52, 1944.

6. POPENHOE, PAUL J., Heredity, 34, , 83, 1943.

7. TITUS, P., J.A.M.A. 105, 1257,1943

8. REYNOLDS, S. R. M. Physiology of the Uterus. Hamish Hamilton,

9. WILlliams, W. W. Connecticut State Med. J., Aug. 1943.

\section{FRACTURES OF THE LOWER LIMB}

\author{
By E. H. Hambly, F.R.C.S. \\ (Surgeon E.M.S. Royal National Orthopaedic \\ Hospital, W.I)
}

\section{Fractures Involving the Hip Joint}

The hip joint is peculiarly affected by injury throughout life from the nature of its position and function.

In the child the chief injuries of this joint are Perthes disease and slipping of the femoral epiphysis. Perthes disease, which occurs in boys between the ages of four to ten, is an aseptic necrosis of the head of the femur. This is secondary to injury in which the blood supply to the femoral head is cut off. See X-Ray, No. I. Treatment consists in absolute rest in bed with strapping extension until the femoral head regains its full circular contour. This usually takes from eighteen months to two years.

Slipping of the epiphysis of the head of the femur occurs between the ages of twelve to fourteen and is commoner in girls. It is frequently a bilateral condition and is associated with the fat type of pituitary disordered child. Diagnosis is confirmed by taking X-rays in the "lithotomy" position. Treatment consists of rest in bed in extension and full abduction until the head of the femur has fused to the neck. (See X-ray No. 2.)

In adults traumatic dislocation of the hip joint is not uncommon. It may be associated with a fracture of the acetabulum. Central fractures of the acetabulum are described in the next article upon fractures of the pelvis. Sciatic paralysis associated with dislocations of the hip are always of poor prognosis. Thirty per cent of dislocated hips show avascular necrosis with secondary gross osteoarthritis. The head of the femur may be dislocated anteriorly or posteriorly.

Clinically, posterior dislocation of the hip puts the leg into abduction and internal rotation. Treatment consists of reduction of the head by flexing the hip at the same time as abducting and externally rotating it. This is best done with the patient on the floor.

The second type of dislocation anteriorly pre- sents itseif with one leg externally rotated and abducted. Reduction is performed by flexion, abduction, and internal rotation of the hip at the $\frac{\mathbb{\Phi}}{2}$ same time lifting the head into the acetabulum.

Following reduction, all dislocations of the hip $\overrightarrow{\vec{F}}$ should be immobilised in a plaster spica to prevent $\stackrel{\text { ? }}{?}$ re-dislocation, and to allow the torn ligaments to heal, and also to minimise myositis ossificans. If the margin of the acetabulum is fractured as well the dislocated hip is best treated on an abduction $\stackrel{\varnothing}{\circ}$ frame. (See X-ray No. 3.)

\section{Fracture of the Neck of the Femur}

A great deal of literature has already accumulated upon this fracture, but the treatment is still far from satisfactory. Fractures of the 3 femoral neck may be classified clinically into three groups. They are inter-trochanteric fractures, trans-cervical fractures which do well with nailing, w and thirdly, those which do not.

Inter-trochanteric fractures always unite easily without operation. (See X-ray No. 4.) These o should be treated by rest in bed in full abduction to prevent the otherwise inevitable coxa vara. $\infty$ External rotation is prevented by a plaster up to $\frac{\mathbb{}}{0}$ the knee to which is fixed a transverse wooden bar $\stackrel{\mathbb{D}}{\vec{D}}$ behind the calf.

Trans-cervical fractures unite easily with nailing $\stackrel{\mathbb{D}}{\stackrel{\mathbb{D}}{-}}$ in some cases, and with great difficulty in othere The first type, which unite easily are abduction of fractures. (See X-ray No. 5.) If these are impacted no operation is necessary. They should be treated by rest, but it is important to $\mathrm{X}$-ray them regularly in the first few weeks in case they become dis-o impacted. If they do so they should be treated $\frac{\mathbb{Q}}{\mathbb{Q}}$ by the insertion of a Smith-Petersen nail.

The third group, which do not unite easily, are adduction fractures. (See X-ray No. 6.)

In this type of fracture the fracture line is more? vertical than horizontal and thus more likely to? slide. Also there is no impaction. Treatmento consists in the insertion of a Smith-Petersen nail? and non-weight bearing for twelve weeks.

A vitallium nail should always be used as stainless steel ones slip out. The writer preferso the almost "blind" method with a two-inch incision to the more complicated Hey-Groves, Engel-May, 응 Eric Lloyd, and other methods. The human hand is extremely accurate in the insertion of the guidewire after practice. X-rays should be taken at八 all stages of the operation, i.e. after reduction, insertion of guide wire, insertion of nail and aftero impaction. (See X-ray Nos. 7 and 8.)

\section{Fractures of Shaft of Femur}

These may be classified into three anatomicaßs types, sub-trochanteric, middle two-thirds of shaft, 